\title{
ULTRASONIC VELOCITY STUDIES OF BENZOIC ACID AND SUBSTITUTED BENZOIC ACIDS IN AQUEOUS MIXED SOLVENT SYSTEMS
}

\author{
S. Jagan Raj ${ }^{1, \bigotimes}$, V. Subha ${ }^{2}$ and S. Bangaru Sudarsan Alwar ${ }^{3}$ \\ ${ }^{1}$ Department of Chemistry, Velammal Institute of Technology, Panchetti, Chennai \\ ${ }^{2}$ Department of Chemistry, R.M.D Engineering College, Kavaraipettai, Chennai \\ ${ }^{3}$ Department of Chemistry, D.G. Vaishnav College, Arumbakkam, Chennai \\ ${ }^{\circledR}$ Corresponding Author: sjaganraj27@gmail.com
}

\begin{abstract}
The ultrasonic velocity of benzoic acid and substituted benzoic acids such as para chloro benzoic acid, para nitro benzoic acid and meta nitro benzoic acid in ethanol-water binary solvent mixtures of several compositions were evaluated. It finds immense applications in the field of several technological and industrial processes such as petrochemical, pharmaceutical and in the manufacture of dyes. The results of ultrasonic velocity determination are remarkably important in the determination of liquid mixtures that are made up of polar and non-polar compounds. The structural modifications of ethanol get into a 3-D network of linkages made up of hydrogen bonds in liquid mixtures. In the present study, it is inferred that a weak molecular association exists between ethanol and the substituted benzoic acids through weak dipole-dipole interactions. The probability of the development of donoracceptor complexes has also been examined and subsequently discussed. In addition, the effect of substituents like the nitro and the chloro group at the para and meta positions has also been interpreted.
\end{abstract}

Keywords: Benzoic Acid, Ultrasonic Velocity, Solute-solvent Interactions

RASĀYAN J. Chem., Vol. 14, No.4, 2021

\section{INTRODUCTION}

The results of ultrasonic velocity studies are extremely useful in identifying the acoustical and thermodynamic parameters that are significantly perceptive to molecular interaction studies. ${ }^{1,2}$ The structure of molecular liquids can be speculated from the results of thermodynamic and transport properties. The results also throw light on the presence of intermolecular interactions that exist in the liquid mixtures.

Alcohols are highly self-associated liquids. Both inter and intramolecular hydrogen bonding is found in alcohols.

The most important property of alcohols is their application as solvents and they are of a major utility in biology, chemistry and pharmaceutical studies. Likewise substituted benzoic acids like p-chloro benzoic acid, m-nitrobenzoic acid and p-nitrobenzoic acid are mainly used in a variety of industrial applications. The 3-D network of hydrogen bonding in alcohols makes it an interesting aspect to highlight the diverse types of molecular interactions and associations in organic ternary mixtures having alcohol, a selfassociated liquid in the mixtures. It can associate with any other compound which has a group that is susceptive to polar associations.

The variation of ultrasonic velocity unravels the changes associated with the structure of the weakly associating and strongly associating components in the binary liquid mixtures. ${ }^{3-5}$ The molecules of benzoic acid are connected by hydrogen bonds and exist as a dimer with $\mathrm{D}_{2} \mathrm{~h}$ symmetry. There are several chances for ethanol to interlink and form a complex which is hydrogen-bonded with benzoic acid and the substituted benzoic acids. The structure may be due to the nature of ethanol which can act both accept hydrogen bonds strongly as well as act as a weak hydrogen bond donor.

Thus, mixing the different substituted benzoic acids in aqueous ethanol mixtures gives interesting results due to the presence of specific interactions that may arise due to the charge-transfer forces, dipole-dipole interactions, donor-acceptor properties and hydrogen bonding of the mixtures. 
RASĀYAN J. Chem.

Vol. 14 | No. 4 |2622-2626| October- December | 2021

\section{EXPERIMENTAL}

Analytical grade and highly pure chemicals purchased from E. Merck, India were used in this study. Standard procedures were used to purify and redistill the solvent. ${ }^{7-9}$ A single crystal variable path interferometer of an accuracy $\pm 0.05 \%$ was used to calculate the ultrasonic velocity of liquid mixtures.

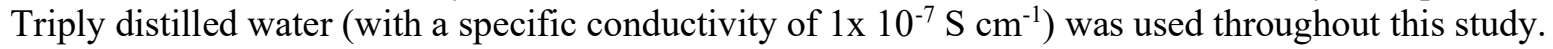

\section{RESULTS AND DISCUSSION}

In this section, the measured results of ultrasonic sound velocity of benzoic acid, $\mathrm{p}$-chloro benzoic acid, $\mathrm{m}$ nitrobenzoic acid and p-nitrobenzoic acid in aqueous ethanolic mixtures at $303.18 \mathrm{~K}$ are interpreted. These values are given in Tables -1 and 2 .

Table1: Experimental Data of Ultrasonic Velocity of $\mathrm{C}_{6} \mathrm{H}_{5} \mathrm{COOH}$ in Ethanol-water Mixtures (v/v)

\begin{tabular}{|c|c|c|c|c|c|c|c|c|}
\hline \multirow[t]{2}{*}{$\begin{array}{c}\text { [Benzoic Acid] } \\
\text { (M) }\end{array}$} & \multicolumn{8}{|c|}{$\begin{array}{c}\text { Experimental Data of Ultrasonic Velocity of } \mathrm{C}_{6} \mathrm{H}_{5} \mathrm{COOH} \text { in Ethanol-water Mixtures (v/v) } \\
\mathrm{U}\left(\mathrm{ms}^{-1}\right)\end{array}$} \\
\hline & $5 \%$ & $10 \%$ & $15 \%$ & $20 \%$ & $25 \%$ & $50 \%$ & $60 \%$ & $80 \%$ \\
\hline $6.25 \mathrm{E}-05$ & 1534.7 & 1542.1 & 1553.3 & 1550.3 & 1566.1 & 1572.7 & 1531.7 & 1399.7 \\
\hline $1.25 \mathrm{E}-04$ & 1536 & 1548.9 & 1555.1 & 1567.3 & 1570.7 & 1587.2 & 1545.9 & 1413.9 \\
\hline $2.50 \mathrm{E}-04$ & 1548.1 & 1554 & 1557.4 & 1574.7 & 1594.5 & 1598.5 & 1561.3 & 1426.3 \\
\hline $5.00 \mathrm{E}-04$ & 1550.1 & 1564.9 & 1560.8 & 1585.5 & 1597.5 & 1630.3 & 1578.6 & 1438.6 \\
\hline $1.00 \mathrm{E}-03$ & 1552 & 1573.1 & 1562.9 & 1600.4 & 1603.7 & 1674.5 & 1594.1 & 1439.1 \\
\hline
\end{tabular}

Table-2: Experimental Data of Ultrasonic Velocity of Substituted Benzoic Acids in Aqueous Ethanol-water Mixtures (v/v)

\begin{tabular}{|c|c|c|c|c|c|c|c|c|c|}
\hline \multirow{3}{*}{$\begin{array}{l}\text { [Concentration] of } \\
\text { the substituted } \\
\text { Benzoic Acid } \\
\text { (M) }\end{array}$} & \multicolumn{9}{|c|}{$\begin{array}{l}\text { The Ultrasonic Velocity of Substituted Benzoic Acids in Aqueous Ethanol-water Mixtures } \\
\qquad(\mathrm{v} / \mathrm{v}) \mathrm{U}\left(\mathrm{ms}^{-1}\right)\end{array}$} \\
\hline & \multicolumn{3}{|c|}{$20 \%$} & \multicolumn{3}{|c|}{$50 \%$} & \multicolumn{3}{|c|}{$80 \%$} \\
\hline & p-CBA & p-NBA & $\begin{array}{c}\mathrm{m}- \\
\mathrm{NBA}\end{array}$ & p-CBA & $\mathrm{p}-\mathrm{NBA}$ & $\begin{array}{c}\mathrm{m}- \\
\mathrm{NBA}\end{array}$ & p-CBA & p-NBA & $\begin{array}{c}\mathrm{m}- \\
\mathrm{NBA}\end{array}$ \\
\hline 0.0001 & 1604 & 1616 & 1614 & 1552 & 1485 & 1600 & 1490 & 1395 & 1579 \\
\hline 0.00005 & 1550 & 1523 & 1602 & 1510 & 1450 & 1590 & 1461 & 1351 & 1512 \\
\hline 0.000025 & 1520 & 1470 & 1596 & 1482 & 1430 & 1578 & 1445 & 1325 & 1490 \\
\hline 0.0000125 & 1504 & 1445 & 1585 & 1470 & 1425 & 1563 & 1440 & 1315 & 1480 \\
\hline
\end{tabular}

Table-1 interprets the results of ultrasonic velocity measurements of benzoic acid in aqueous ethanol mixtures. Figure-1 illustrates the outcomes of ultrasonic velocity measurements of benzoic acid in aqueous ethanol mixtures. Table- 2 infers the results of ultrasonic velocity measurements of the substituted benzoic acids in aqueous ethanol mixtures. Figures-2, 3 and 4 represent the variation of ultrasonic velocity with a concentration of the substituted benzoic acids in different volume fractions of ethanol and water respectively. It is observed that with a raise in the molar concentration of the solute, there is a trivial increase in the ultrasonic velocity. The increase in ultrasonic velocity was observed for benzoic acid and substituted benzoic acids until 50\%, which then decreases. The difference in ultrasonic velocity can be directly related to the changes in the intermolecular free length. The same trend in results is also reported earlier by several researchers. ${ }^{3-6}$ The ultrasonic velocities of the acids decrease at all concentrations at $80 \%$ volume fractions of ethanol-water media.

Literature reports from X-ray diffraction, mass spectroscopic and spectroscopic analysis ${ }^{10-12}$ highlight the results of ethanol-water mixtures. It is expected that the solvation behavior is primarily due to the solutesolvent interactions. However, literature reports ${ }^{10}$ underline that the solvation behavior of ethanol-water mixtures is due to the clustering structure of the mixed solvent system. The bulk water structure completely breaks down at higher ethanol compositions. ${ }^{11}$ It is also known that at a selected mole fraction of ethanol $\left(\mathrm{X}_{\mathrm{E}}>0.15\right)$, a huge set of hydrogen bonds are produced between the water and ethanol molecules. This can also be portrayed by a cluster model which can be visualized as a piled ethanol core encircled by a thin water shell. ${ }^{10-12}$ 


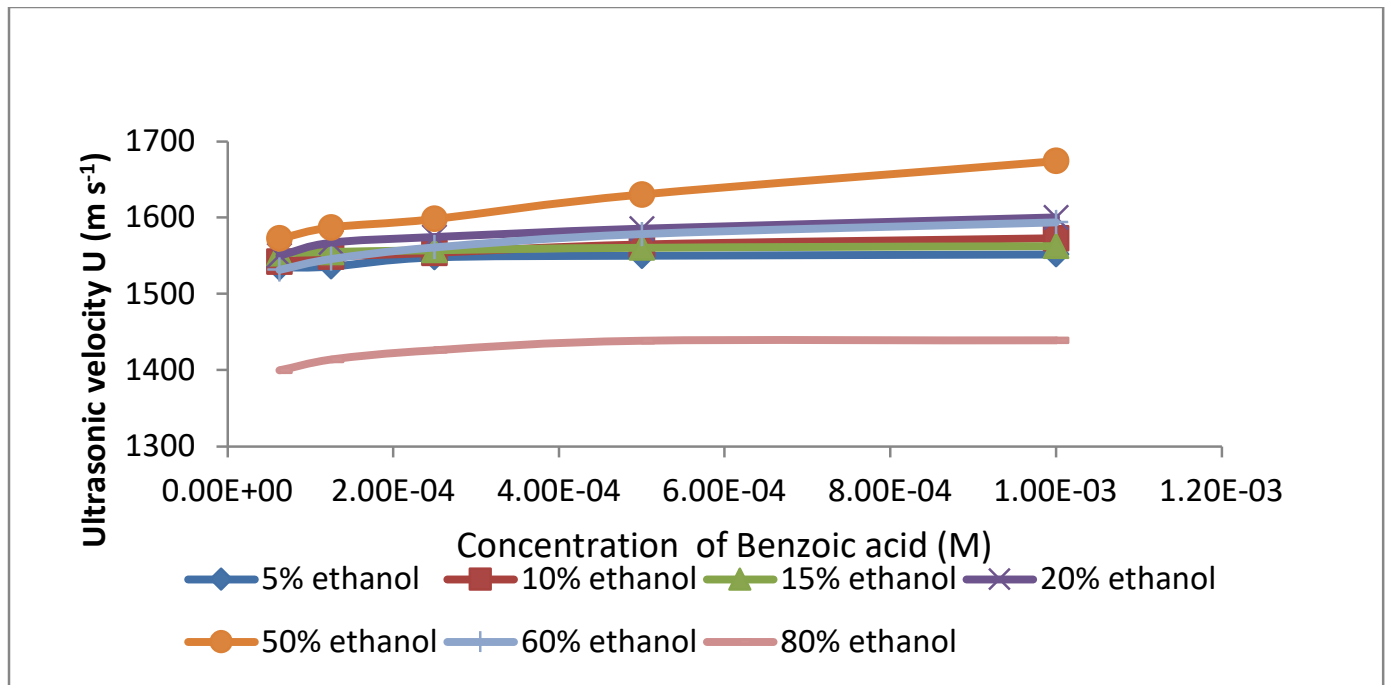

Fig.-1: Ultrasonic Velocity measurements for the Variation of Ultrasonic Velocity of $\mathrm{C}_{6} \mathrm{H}_{5} \mathrm{COOH}$ in Ethanol-water Media (v/v)

The addition of benzoic acid to water molecules initially disturbs the structure of water which eventually leads to certain structural changes in the solution that produce closely fitting helical cavities ${ }^{13}$. In lower proportions of ethanol, benzoic acid and the substituted benzoic acids dissociate into their corresponding ions in the solution. The ultrasonic velocity initially increases which is due to the strong electrostatic interactions amongst the benzoate ions and water molecules. The structural changes may be in agreement with the tendency of ethanol which can both accept hydrogen bonds, as well as donate hydrogen bonds. Thus as reported earlier, increased ionic hydration and cohesion in the medium is hence expected.

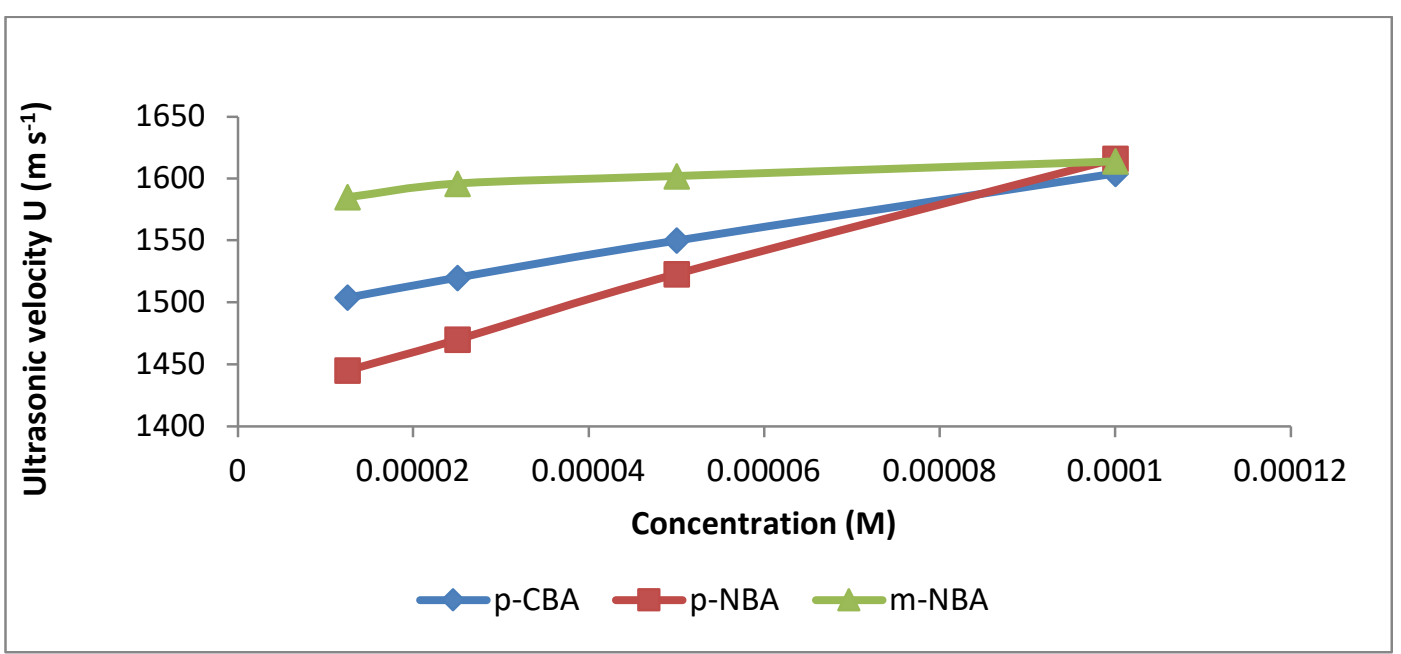

Fig.-2: Ultrasonic Velocity measurements for substituted Benzoic Acids in 20\% Volume Fractions of Ethanol

As the concentration of the solution increases, all the three substituted benzoic acids such as p-CBA, $\mathrm{p}$ NBA and m-NBA show an increase in ultrasonic velocity. It is seen from Figures-2, 3 and 4 that p-NBA showed the greatest increase in velocity. At 50\% fraction of ethanol-water media, m-NBA displayed higher velocity values than p-CBA and p-NBA (Fig.-3). However, m-NBA reveals higher velocity at $80 \%$ volume fractions of ethanol in the solution (Fig.-4). The highest velocity is observed in m-NBA relative to p-NBA and $\mathrm{p}-\mathrm{CBA}$. The results denote the presence of strong intermolecular interactions between $\mathrm{m}-\mathrm{NBA}$ and ethanol-water molecules in comparison to p-NBA and p-CBA. It is also inferred that for all the three substituted benzoic acids the solute-solvent interactions predominates at fractions of ethanol less than 50\% and solvent-solvent interactions predominate after $50 \%$ of ethanol. This is attributed to the breaking down of the structure of water at such greater compositions. ${ }^{14}$ As the substituted benzoic acids dissolve in greater 
RASĀYAN J. Chem.

Vol. 14 | No. 4 |2622-2626| October- December | 2021

proportions of ethanol to form a miscible solution at any proportion, there is an association of the intermolecular attractive forces, as like dissolves like. The results of ultrasonic velocity probe into the extent of molecular interactions existing in the system due to solvation which may be of tremendous use in a number of industrial processes like the petrochemical and the pharmaceutical industry.

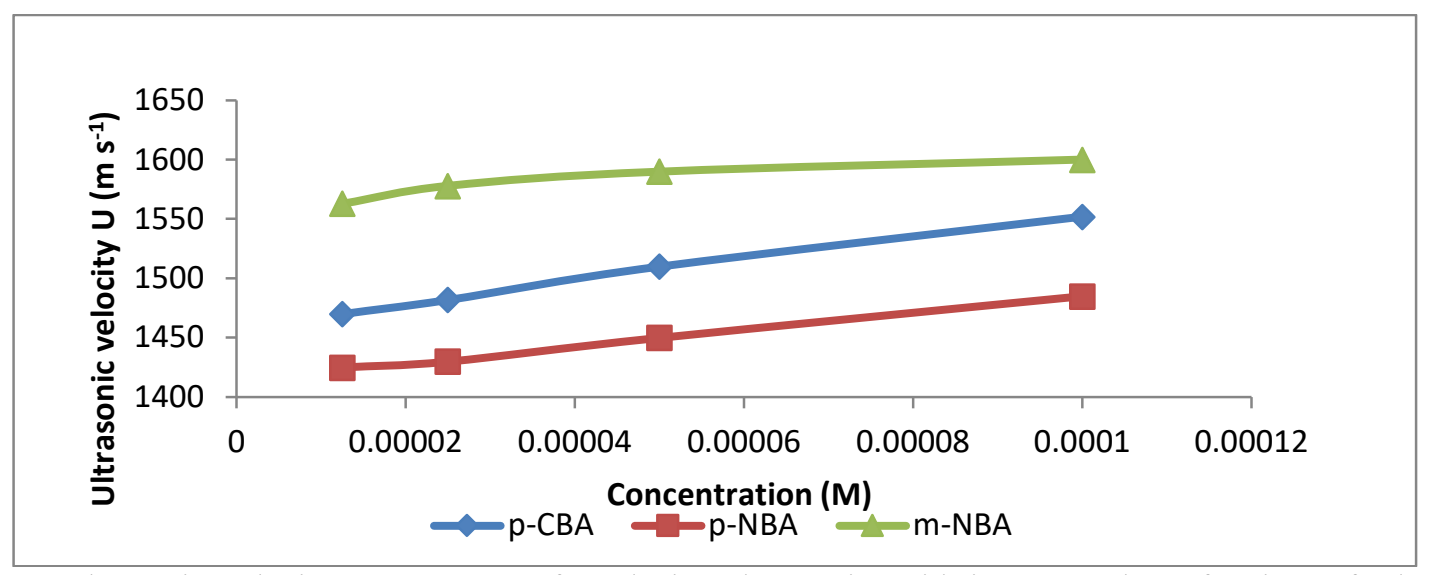

Fig.-3: Ultrasonic Velocity measurements for substituted Benzoic Acids in 50\% Volume fractions of Ethanol

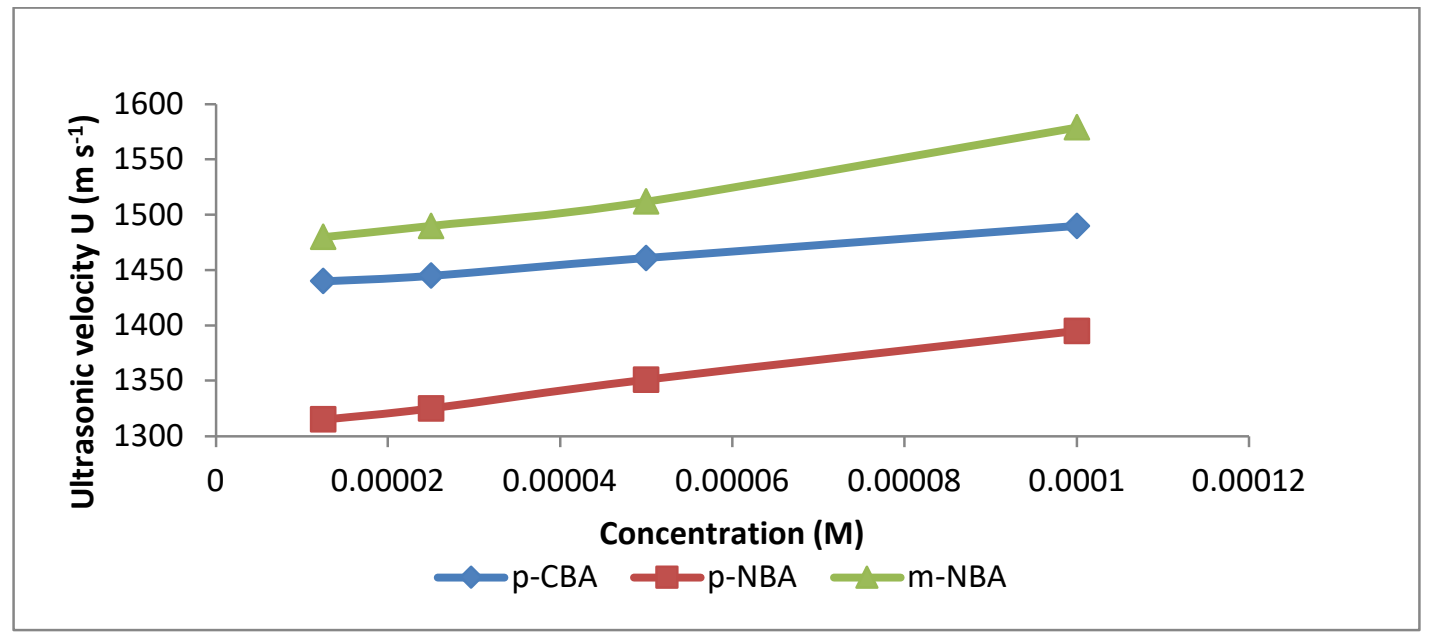

Fig.-4: Ultrasonic Velocity measurements for substituted Benzoic Acids 80\% Volume fractions of Ethanol

\section{CONCLUSION}

Owing to these physical parameters of substituted benzoic acids, alcohol and water, the present study of molecular interaction studies of substituted benzoic acids in the binary solvent mixtures of ethanol and water has been carried out. Although extensive work has been carried out about the reactivity of several compounds in binary solvent mixtures, the study of substituted benzoic acids in such mixtures is really rare. The collective effect of alcohol and water as binary solvents in which substituted benzoic acids were added as solutes at various mole fractions has been an unusual study and almost no systematic reports were carried out earlier. The acoustical properties of liquid binary mixtures were extensively carried out to examine the variation of the binary mixtures from ideality. The structure, nature and geometry of both the solvent and solute molecules decide the amount of molecular interactions present in a system. The acoustical properties of systems containing ethanol-water mixtures with both benzoic acid and substituted benzoic acids throw light on the impact of molecular interaction on the structure of the compounds in the liquid mixtures.

\section{REFERENCES}

1. S.K.Mehta and R.K. Chauhan, Journal of Solution Chemistry, 26(3), 295(1997), https://doi.org/10.1007/bf02768000 
2. R.K. Dewan, S.K. Mehta and J. Singh, Acta Acustica United with Acustica, 74(4),284(1991).

3. K.Govinda Rao and Shaik Babu, Rasayan Journal of Chemistry, 12(3), 1909(2019), http://dx.doi.org/10.31788/RJC.2019.1245481

4. G.Arul. and L. Palaniappan, Journal of the Acoustical Society of India, 28, 393(2000).

5. D. Bala Karuna Kumar, K. Rayapa Reddy, G. Srinivasa Rao, G.V. Rama Rao and C. Rambabu, Asian Journal of Chemistry, 24(5), 2239(2012).

6. S.Jagan Raj, V.Subha and Bangaru Sudarsan Alwar, Journal of Chemical, Biological and Physical Science, 2(4), 650(2017)

7. B. Ravinder Reddy, Y. HariBabu, D. Linga Reddy, Indian Journal of Pure and Applied Physics, 37, 13(1999).

8. A.I.Vogel, Textbook of Practical Organic Chemistry, $3^{\text {rd }}$ Edition, Longmans, London, (1959).

9. I.A.Riddich, W.B. Banger, Organic Solvents (Wiley-InterSience), New York, (1970).

10. K.Egashira, and N.Nishi, The Journal of Physical Chemistry B, 102(21), 4054 (1998), https://doi.org/10.1021/jp9806359

11. N.Nishi, S.Takahashi,M. Matsumoto, A.Tanaka, K. Muraya, T.Takamuku and T.Yamaguchi, The Journal of Physical Chemistry, 99 (1), 462(1995), https://doi.org/10.1021/j100001a068

12. A.Wakisaka, S. Komatsu and Y.Usui, Journal of Molecular Liquids, 90(1-3), 175(2001). https://doi.org/10.1016/S0167-7322(01)00120-9

13. J.Kavanu, "Water and Water Soluble Water Interactions(Holder-Day Amsterdam)", Available at: http://www.irdindia.in/journal ijacsa/pdf/vol2 iss4/9.pdf (accessed 10 July 2017),(1964).

14. A.Bhattarai, and S.S. Kumar, Research Journal of Chemical Sciences, 1(6), 482,(2011).

[RJC-5767/2020] 